\title{
Human disturbance caused stronger influences on global vegetation change than climate change (\#37648)
}

First revision

\section{Guidance from your Editor}

Please submit by 24 Aug 2019 for the benefit of the authors (and your \$200 publishing discount).

\section{Structure and Criteria}

Please read the 'Structure and Criteria' page for general guidance.

\section{-.. Author notes}

Have you read the author notes on the guidance page?

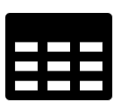

\section{Raw data check}

Review the raw data. Download from the location described by the author.

\section{Image check}

Check that figures and images have not been inappropriately manipulated.

Privacy reminder: If uploading an annotated PDF, remove identifiable information to remain anonymous.

\section{Files}

Download and review all files from the materials page.
1 Tracked changes manuscript(s)

1 Rebuttal letter(s)

6 Figure file(s)

1 Table file(s) 


\section{Structure your review}

The review form is divided into 5 sections. Please consider these when composing your review:

\section{BASIC REPORTING}

2. EXPERIMENTAL DESIGN

3. VALIDITY OF THE FINDINGS

4. General comments

5. Confidential notes to the editor

You can also annotate this PDF and upload it as part of your review

When ready submit online.

\section{Editorial Criteria}

Use these criteria points to structure your review. The full detailed editorial criteria is on your guidance page.

\section{BASIC REPORTING}

Clear, unambiguous, professional English language used throughout.

Intro \& background to show context. Literature well referenced $\&$ relevant.

Structure conforms to Peer] standards, discipline norm, or improved for clarity.

Figures are relevant, high quality, well labelled \& described.

Raw data supplied (see Peer] policy).

\section{EXPERIMENTAL DESIGN}

Original primary research within Scope of the journal.

Research question well defined, relevant \& meaningful. It is stated how the research fills an identified knowledge gap.

Rigorous investigation performed to a high technical \& ethical standard.

Methods described with sufficient detail \& information to replicate.

\section{VALIDITY OF THE FINDINGS}

Impact and novelty not assessed.

Negative/inconclusive results accepted. Meaningful replication encouraged where rationale $\&$ benefit to literature is clearly stated.

All underlying data have been provided; they are robust, statistically sound, $\&$ controlled.
Speculation is welcome, but should be identified as such.

Conclusions are well stated, linked to original research question $\&$ limited to supporting results. 


\section{Standout \\ reviewing tips}

The best reviewers use these techniques

Tip

\section{Support criticisms with evidence from the text or from other sources}

\section{Give specific suggestions on how to improve the manuscript}

\section{Comment on language and grammar issues}

\author{
Please provide constructive \\ criticism, and avoid personal \\ opinions
}

\section{Example}

Smith et al (J of Methodology, 2005, V3, pp 123) have shown that the analysis you use in Lines 241-250 is not the most appropriate for this situation. Please explain why you used this method.

Your introduction needs more detail. I suggest that you improve the description at lines 57- 86 to provide more justification for your study (specifically, you should expand upon the knowledge gap being filled).

The English language should be improved to ensure that an international audience can clearly understand your text. Some examples where the language could be improved include lines 23, 77, 121, 128 - the current phrasing makes comprehension difficult.

1. Your most important issue

2. The next most important item

3....

4. The least important points

I thank you for providing the raw data, however your supplemental files need more descriptive metadata identifiers to be useful to future readers. Although your results are compelling, the data analysis should be improved in the following ways: $A A, B B, C C$

I commend the authors for their extensive data set, compiled over many years of detailed fieldwork. In addition, the manuscript is clearly written in professional, unambiguous language. If there is a weakness, it is in the statistical analysis (as I have noted above) which should be improved upon before Acceptance.
Comment on strengths (as well as weaknesses) of the manuscript 


\title{
Human disturbance caused stronger influences on global vegetation change than climate change
}

\author{
Xianliang Zhang ${ }^{\text {Corresp., 1, } 2 \text {, Xuanrui Huang }}{ }^{1,2}$ \\ ${ }^{1}$ College of Forestry, Hebei Agricultrual University, Baoding, China \\ 2 Long-term Forest Silviculture Research Station in Saihanba, Chengde, China \\ Corresponding Author: Xianliang Zhang \\ Email address: zhxianliang85@gmail.com
}

Global vegetation distribution influenced by human disturbance and climate change. The past vegetation changes were studied in numerous studies while few studies had addressed the relative contributions of human disturbance and climate change on vegetation change. To separate the influences of human disturbance and climate chang on the vegetation changes, we compared the existing vegetation which indicates the vegetation distribution under human influences with the potential vegetation which reflects the vegetation distribution without human influences. The results showed that climate-induced vegetation changes only occurred in a few grid cells from the period 1982-1996 to the period 1997-2013. Human-induced vegetation changes occurred worldwide, except in the polar and desert regions. About $3 \%$ of total vegetation distribution was transformed by human activities from the period 1982-1996 to the period 1997-2013. Human disturbances caused stronger damage to global vegetation change than climate change. Our results indicated that the regions where vegetation experienced both human disturbance and climate change are eco-fragile regions. 


\section{Human disturbance caused stronger influences on global vegetation} change than climate change

$4 \quad{ }^{1}$ College of Forestry, Hebei Agricultural University, Baoding 071001, China

$5 \quad{ }^{2}$ Long-term Forest Silviculture Research Station in Saihanba, Chengde 067000, China

7 Correspondence Author:

$8 \quad$ Xianliang Zhang

9289 Lingyusi street, Lianchi District, Baoding, 071001, China

10 Email address: 1xzhxl@hebau.edu.cn

11

12 
13 Abstract. Global vegetation distribution was influenced by human disturbance and climate

14 change. The past vegetation changes were studied in numerous studies while few studies had

15 addressed the relative contributions of human disturbance and climate change on vegetation

16 change. To separate the influences of human disturbance and climate changes on the vegetation $P$

17 changes, we compared the existing vegetation which indicates the vegetation distribution under

18 human influences with the potential vegetation which reflects the vegetation distribution without

19 human influences. The results showed that climate-induced vegetation changes only occurred in

20 a few grid cells from the period 1982-1996 to the period 1997-2013. Human-induced vegetation

21 changes occurred worldwide, except in the polar and desert regions. About $3 \%$ of total

22 vegetation distribution was transformed by human activities from the period 1982-1996 to the

23 period 1997-2013. Human disturbances caused stronger damage to global vegetation change than

24 climate change. Our results indicated that the regions where vegetation experienced both human

25 disturbance and climate change are eco-fragile regions.

26 
1 Introduction

Vegetation is the most important component of the global terrestrial ecosystem. Influenced

29 by human disturbance and climate changes, global vegetation has shifted from a semi-wild

30 terrestrial biosphere to a mostly anthropogenic biome (Ellis et al., 2010). The changes in the

31 global vegetation or land use in the past were addressed in numerous studies (e.g. Wang et al.

32 2006; Li et al. 2017; Song et al. 2018). However, few studies evaluated the individual

33 contributions of human disturbance and climate change on vegetation changes, which is crucial

34 to know whether the past vegetation changes are mainly caused by human or nature.

35 Human disturbances and climate change are the two main factors that determine the

36 changes in regional vegetation distribution. The land surface of the Earth has been modified by

37 human activities (e.g. farming, construction and grazing) for centuries, and it has been

38 significantly changed by human activities (Foley et al., 2005; Ellis and Ramankutty, 2008;

39 Defries et al., 2010). More of the land surface is being transformed as the human population

40 continues to increase (Goldewijk et al., 2011; Eills et al., 2013). The new geological epoch has

41 been referred to as the Anthropocene (Lewis and Maslin 2015) and the period in which biomes

42 have been severely transformed by human disturbance is referred to as an anthrome (Eills and $\bigcirc$

43 Ramankutty, 2008). With the continuous expanding human settlements, the distribution of

44 vegetation types across the globe has changed markedly compared with the potential distribution

45 of vegetation types which reflect vegetation distribution in the absence of anthropogenic

46 influences.

Peer] reviewing PDF | (2019:05:37648:1:1:NEW 1 Aug 2019) 
47 Climate changes is another factor that causes shifts in the vegetation distribution (Kelly et al.,

48 2008). Climate change had strong influences on the transformation of the vegetation distribution.

49 Tropical rainforest and arctic tundra have experienced boundary changes as a result of climatic

50 change (Diaz and Eischeid, 2007; Cook and Vizy, 2010; Zhang and Yan, 2014a). Widespread

51 forest die-off from drought and heat stress increased with climate changes (Allen et al., 2010;

52 Anderegg et al., 2013). Some dying forests are likely to be replaced by other vegetation types.

53 For instance, boreal forests are experiencing the strongest warming among forest ecosystems,

54 and large area of boreal forest are expected to be replaced by other biomes (Gauthier et al., 2015).

55 Vegetation distribution change would be severe with continuous climate warming.

56 The anthropogenic transformation of biomes and the terrestrial biosphere has been

57 investigated to reflect vegetation distribution changes by comparing different biomes at century

58 intervals (Ellis et al., 2010, 2011), without considering the contribution of climate changes on

59 shifting the vegetation. In addition, climate data (1700-2000) used to detect the anthropogenic

60 transformation of biomes was almost 20 years ago (Ellis et al., 2010). The updated analysis is

61 urgently need as the climate changes plays an important role in shifting the vegetation.

62 In this study, we delimit the influence of human disturbance and climate on the distribution

63 of vegetation based on updated data from 1982 to 2013. Accordingly, our main goals were to (1)

64 delineate the influence of human disturbance versus climate on the vegetation distribution, and (2)

65 identify those regions most susceptible to human disturbance in recent period.

\section{Data and methods}




\section{$67 \quad 2.1$ Climate and vegetation data}

68 Global gridded monthly mean temperature and total precipitation data were obtained from

69 the CRU TS 4.01 dataset at $0.5^{\circ} \times 0.5^{\circ}$ resolution (Harris et al., 2014). This dataset interpolates

70 climate data from meteorological stations distributed throughout the world to the global land area,

71 grid-by-grid, for the period 1901-2013 and has been used in previous climate classifications

72 (Zhang and Yan, 2014a). We used climate data for the period 1982-2013 as this period reflected

73 the availability of the vegetation data.

74 The normalized difference vegetation index (NDVI) has been used to indicate the greenness

75 of vegetation in numerous vegetation studies (e.g. Breshears et al., 2005, Tucker et al., 2005,

76 Zhou et al., 2014). As a coarse measure, the differences in NDVI may mask changes to

77 vegetation species composition, however, it has limited influences on identifying vegetation

78 types. It is defined as

$$
\mathrm{NDVI}=(\mathrm{NIR}-\mathrm{RED}) /(\mathrm{NIR}+\mathrm{RED}),
$$

80 where NIR and RED are the amounts of radiation in the near-infrared and red regions,

81 respectively. The NIR and RED reflectances should be corrected for atmospheric effects. The

82 NDVI values range from -1 to 1 , where negative values correspond to an absence of vegetation

83 and positive values indicate vegetated land.

84 Monthly mean NDVI data at $0.0833^{\circ} \times 0.0833^{\circ}$ spatial resolution were retrieved from the

85 Advanced Very High Resolution Radiometer (Pinzon and Tucker, 2014) based Global Inventory

86 Modelling and Mapping Studies dataset (https://ecocast.arc.nasa.gov/data/pub/gimms/3g.v0/) for 
87 the period 1982-2013.

88 The high-resolution climate data was not available for the vegetation classification. Hence,

89 the NDVI data was up-scaled to match the resolution of climate data. The NDVI data were up-

90 scaled by calculating the arithmetic mean of the nearest neighbor grids over a six-by-six window

91 because one grid cell of climate data $\left(0.5^{\circ} \times 0.5^{\circ}\right)$ covers six-by-six grid cells in NDVI data

$92\left(0.0833^{\circ} \times 0.0833^{\circ}\right)$.

93 2.2 Separation of climate- and anthropo- driven vegetation changes

94 How to delimit the influence of human disturbance and climate on the vegetation was

95 outlined in the sketch of Fig.1. The vegetation distribution in the real world could be represented

96 by existing vegetation types which reflected the vegetation distribution under human influences

97 (Zhang et al., 2017a). Existing vegetation types include effects of human influences while

98 potential vegetation types exclude these effects. The real vegetation changes could be identified

99 by the changes in existing vegetation over the two periods. The potential vegetation changes are

100 mainly caused by climate changes. The climate-driven vegetation changes could be reflected by

101 the changes in potential vegetation over different periods. The anthropo-driven vegetation

102 changes can be identified by the difference between the changes in potential and existing

103 vegetation.

$104 \quad 2.3$ Potential vegetation distribution

105 The potential vegetation was generally defined based on climate variables (Koeppen 1936;

106 Holdridge 1947; Box 1996; Ramankutty and Foley, 1999; Beck et al., 2005; Baker et al., 2010;

Peer) reviewing PDF | (2019:05:37648:1:1:NEW 1 Aug 2019) 
107 Ellis et al., 2010; Levavasseur et al., 2012), therefore, the potential vegetation types could be

108 represented by corresponding climate types. Climate types could be objectively classified to

109 different global climate types based on the monthly attributes using the K-means clustering

110 method (Mahlstein and Knutii, 2010; Zhang and Yan, 2014a, b; Zhang and Yan, 2016; Zhang et

111 al., 2017b). Monthly mean temperature and monthly total precipitation were used as input

112 multivariables that consisted of an $n \times 24$ matrix X1:

$$
\mathbf{X} 1=\left[\begin{array}{cccccc}
T_{11} & \cdots & T_{1 m} & P_{11} & \cdots & P_{1 m} \\
\vdots & \vdots & \vdots & \vdots & \vdots & \vdots \\
T_{n 1} & \cdots & T_{n m} & P_{n 1} & \cdots & P_{n m}
\end{array}\right]
$$

114 where $T$ is monthly mean temperature, $P$ is monthly mean precipitation, $m$ is 12 , and $n$ is the

115 number of all the grid cells in the global land area, except the Antarctic. The rows in X1

116 represent the monthly attributes, while the columns represent the number of grid cells. The

117 names of vegetation types were designated by referring to the Koeppen classification (Kottek et

118 al., 2006).

\section{$119 \quad 2.4$ Existing vegetation distribution}

The existing vegetation types were classified based on climate and NDVI data using the Kmeans method (Zhang et al., 2017a). An $n \times 36$ matrix X2 was constituted by monthly mean temperature, monthly total precipitation and monthly mean NDVI:

$$
\mathbf{X} 2=\left[\begin{array}{ccccccccc}
T_{11} & \cdots & T_{1 m} & P_{11} & \cdots & P_{1 m} & \mathrm{NDVI}_{11} & \cdots & \mathrm{NDVI}_{1 m} \\
\vdots & \vdots & \vdots & \vdots & \vdots & \vdots & \vdots & \vdots & \vdots \\
T_{n 1} & \cdots & T_{n m} & P_{n 1} & \cdots & P_{n m} & \mathrm{NDVI}_{n 1} & \cdots & \mathrm{NDVI}_{n m}
\end{array}\right]
$$

124 where $T$ is monthly mean temperature, $P$ is monthly mean precipitation, NDVI is monthly mean

125 NDVI, $m$ is 12 , and $n$ is the number of all the grid cells in the global land area, except the 
126 Antarctic.

127 2.5 Temporal changes in the influences of human disturbance and climate change on 128 vegetation distribution

129 Fraedrich et al., (2001) suggested that an interval of at least 15 years is required to detect

130 temporal changes in the geographical distribution of climate types. Thus, the period from 1982 to

1312013 was split into two periods (1982-1996 and 1997-2013), and the existing and potential

132 vegetation types were classified over the two periods to check the temporal changes in the

133 influences of human disturbance and climate change on vegetation distribution.

134 The differences between the existing vegetation distribution and the potential vegetation

135 distribution over the period 1982-1996 reflected the vegetation changes from no human

136 influence period to the period 1982-1996. The differences between the existing vegetation over

137 two periods 1982-1996 and 1997-2013 reflected the existing vegetation changes from the period

$138 \quad 1982-1996$ to the period 1997-2013.

139 The potential vegetation changes were indicated by the changes in climate types over the

140 two periods. However, whether or not the potential vegetation change was reflected in the real

141 vegetation changes should be verified by checking the overlapped changes in both potential

142 vegetation and existing vegetation. When changes were detected in both the potential and

143 existing vegetation, they were identified as the influence of climate changes on vegetation. The

144 impacts of human disturbance on the vegetation distribution could be identified by the

145 differences between the existing vegetation changes and the potential vegetation changes. 
3 Results

147 Global existing vegetation types were defined for the period 1982-1996 (Fig. 2A) and the

148 period 1997-2013 (Fig. 2B). Changes in the distribution of existing vegetation were found

149 worldwide, except in the polar and desert regions, from the period 1982-1996 to the period

150 1997-2013 (Fig. 2C). The largest changes in vegetation types were found in central Africa,

151 eastern China, western America and Australia. The least changes in the vegetation were found in

152 tropical rainforest, tropical and temperate deserts, frigid deciduous coniferous forest and polar

153 frost.

154 The distribution of potential vegetation over the period 1982-1996 (Fig.3A) was similar to

155 that over the period 1997-2013 (Fig.3B). Changes in potential vegetation mainly occurred on the

156 boundaries between adjacent types of vegetation from the period 1982-1996 to the period 1997-

1572013 (Fig. 3C). Obvious boundary changes were seen between tropical rainforests and tropical

158 dry forests, between tropical deserts and the Sahel, and between temperate deciduous and

159 evergreen forests. After compared with the existing vegetation changes, actual changes in

160 exsiting vegetation caused by climate variations were only detected in a limited number of grid

161 cells (Fig. 3D). These grid cells were distributed worldwide, mainly in the ecotones.

162 Large area of vegetation was transformed by human disturbances (Fig.4C) by changing the

163 potential vegetation (Fig.4B) to the existing vegetation (Fig.4A) from no human influence period

164 to the period 1982-2013. The impact of human disturbance on the vegetation distribution

165 occurred worldwide from the period 1982-1996 to the period 1997-2013 (Fig. 5). The human- 
166 induced vegetation changes were not only seen at the boundaries of vegetation types, but also

167 within the regions of vegetation types. About $3 \%$ of total vegetation distribution was transformed

168 by human activities from the period 1982-1996 to the period 1997-2013. The largest changes in

169 vegetation were found in the eastern China, central Africa and western America.

170 Eastern China was selected to verify our results (Fig. 6). The NDVI changed from -0.04 to

1710.04 in the grid cells where the changes in existing vegetation occurred (Fig. 6B). The changes in

172 vegetation type were verified by the changes in the NDVI (Fig. 6C). The vegetation changed in

173 the regions where the changes in vegetation types were detected. The actual vegetation changes

174 were compared with the land use change between 1990 and 2000 reported by Liu et al. (2002,

175 Fig. 6D). The vegetation changes detected by two studies were mainly concentrated in similar

176 regions. The areal changes in certain vegetation types were similar to those obtained using Liu's

177 land use data (Table. 1). Larger changed areas of vegetation types were detected in this study

178 than in Liu et al., (2002), because more detailed changes in land use could be detected using the

179 land use data with higher resolution and more detailed vegetation types (24 types).

\section{Discussion}

181 The relative contributions of human disturbance and climate change on the vegetation

182 changes was separated by comparing the differences between existing vegetation and potential

183 vegetation. Potential vegetation distribution is the vegetation without human disturbances, and it

184 was similar to potential natural vegetation in 1700 as defined by Ramankutty and Foley (1999)

185 and Ellis et al., (2010). The existing vegetation types were classified based on both vegetation 
186 and climate data to reflect the connection between vegetation and climate, without using the

187 method that defines the vegetation types based on NDVI data (DeFries and Townshend, 1994;

188 Lu et al., 2003). Potential vegetation types and their corresponding existing vegetation types

189 were easily compared because they were classified by the same method.

190 Human disturbance has influenced vegetation for several centuries. The human-induced

191 vegetation changes from no human influenced period to the period 1982-2013 was similar to

192 those reported human-induced land degradation (Bai et al., 2008). The transformations of

193 vegetation caused by human activities mainly through farming, construction and grazing (Barger

194 et al., 2018). The vegetation was mainly transformed into cropland, pasture and constructions

195 due to human activities (Ellis et al., 2011). Transitions in land use before 1900 mainly occurred

196 in China, India, Europe, North America and Australia (Ellis et al., 2010). Transformations in the

197 distribution of vegetation accelerated when rapid growth in the human population increased the

198 pressure to expand the amount of pasture and farmland. These regions are the key zones with

199 respect to the anthropogenic transformation of vegetation from the no human influence period to

200 the period 1982-2013.

201 The impacts of human disturbance on vegetation were seen worldwide from the period

202 1982-1996 to the period 1982-2013, except for the polar and desert regions. The areas that were

203 most affected by human disturbance were those with the highest population densities, including

204 Europe, western North America, Central Africa, southern South American, eastern Australia and

205 eastern China. The expansion of pasture mainly took place in central Asia, Australia, southern 
206 Africa and in the tropical Sahel and subsequent overgrazing led to transformations in the

207 vegetation cover. The amount of cropland has expanded markedly in North and South America,

208 Europe, southern Australia, northeast China and southern Asia. Grassland has been replaced by

209 farmland in Europe and in North and South America. Cropland has expanded into the shrublands

210 of Australia. The main change in land use in eastern China has been the replacement of forest

211 and grassland with cropland (Zhang et al., 2016; Zhang et al., 2017c). However, human

212 disturbances which only influenced the vegetation structure could not be reflected by our results

213 because no shift in vegetation types could be detected.

214 The boundaries of some potential vegetation types were altered by climate changes. A

215 shifting of ecotones seems more likely the result of climate change influencing areas that are

216 borderline based on climate, thus, a small shift in climate is likely to result in a change in

217 ecotones rather than in central vegetation areas. The vegetation in these ecotones was under

218 pressure and would show further changes over time. However, the influence of climate change

219 on vegetation was limited from the period 1982-1996 to the period 1997-2013 because climate-

220 induced vegetation shift was not viable over short periods, except when there was an abrupt

221 climate shift. Moreover, the coarse resolution of the data restricted to detect the detail vegetation

222 changes induced by climate changes. Climate warming and hot drought would likely to cause

223 structure changes of regional vegetation (Breshear et al., 2005; Allen et al., 2011), not vegetatio

224 type change (e.g. forest to grassland), which could not be visible over a short period. However,

225 widespread increased tree mortality has been found in some forest ecosystems because of climate 
226 warming (Adams et al., 2010; Van Mantgem et al., 2009), and large area of vegetation showed

227 greening or browning trends (De Jong et al. 2013). The impact of climate change on vegetation

228 would be more visible in these regions over a longer period (e.g. 200 years).

229 The vegetation would return to what kind of potential forest type if there is no human

230 disturbance can be referred by the potential vegetation types. The potential vegetation type can

231 restore itself over a period with either limited or no human interference. For instance, abandoned

232 farmland in northeast China can transform back to forest cover. These transformations caused

233 fundamental vegetation changes, and could be reflected in our results. There is a large potential

234 in global tree restoration if human disturbance was limited, which is consistent with the results

235 reported by Bastin et al. (2019).

236 The global existing vegetation was seriously transformed from the period 1982-1996 to the

237 period 1997-2013. About 3\% of global vegetation changes their types in the past 30 years.

238 Human disturbance caused server vegetation changes than climate change, which is consistent

239 with a study in northern forest (Danneyrolles et al. 2019). However, the influences of climate

240 changes on vegetation distribution could not be ignored. The regions that were influenced by

241 both human disturbance and climate change are vulnerable to vegetation changes in the future.

2425 Conclusion

243 The effects of human disturbance and climatic change on the distribution of global

244 vegetation types could be separated using the proposed method. A large area of vegetation was

245 transformed by human disturbances from no human influenced period to the period 1982-2013. 
246 About 3\% of total vegetation distribution was transformed by human activities from the period

247 1982-1996 to the period 1997-2013. However, the influence of climate change on vegetation was

248 limited from the period 1982-1996 to the period 1997-2013. Therefore, human disturbances

249 caused stronger damage to global vegetation change than climate change.

250 


\section{References}

252 Adams, H.D., Macalady, A.K., Breshears, D.D., Allen, C.D., Stephenson, N.L., Saleska, S.R.,

253 Huxman, T.E. (2010), Climate-induced tree mortality: Earth system consequences, Eos,

254 Transactions American Geophysical Union, 91, 153-154,

255 Allen, C. D., Macalady, A. K., Chenchouni, H., Bachelet, D., Mcdowell, N., Vennetier, M.,

256 Kitzberger, T., Rigling, A., Breshears, D. D., and Hogg, E. H. (2010), A global overview of

257 drought and heat-induced tree mortality reveals emerging climate change risks for forests, Forest

258 Ecol. Manag., 259, 660-684,

259 Anderegg, W. R. L. and Kane, J. M. and Anderegg, L. D. L. (2013), Consequences of 260 widespread tree mortality triggered by drought and temperature stress, Nat. Clim. Change, 3, 30-

26136

262 Bai, Z., Dent, D. L., Olsson, L., \& Schaepman, M. E. (2008) Proxy global assessment of land 263 degradation, Soil Use Manage., 24(3), 223-234

264 Bastin, J., Finegold, Y., Garcia, C., Mollicone, D., Rezende, M., Routh, D., Zohner, C. M.,

265 Crowther, T. W. (2019) The global tree restoration potential. Science 365:76-79

266 Barger, N. N., Gardner, T. A., Sankaran, M., Belnap, J., Broadhurst, L., Brochier, V., Isbell, F.,

267 Meyfroidt, P., Moreira, F., Nieminen, T. M., Okuro, T., Rodrgiues, R. R.,

268 Saxena, V., and Ross, M. Chapter 3: Direct and indirect drivers of land degradation and 269 restoration. In IPBES (2018): The IPBES assessment report on land degradation and restoration.

270 Montanarella, L., Scholes, R., and Brainich, A. (eds.). Secretariat of the Intergovernmental 
271 Science-Policy Platform on Biodiversity and Ecosystem Services, Bonn, Germany, pp. 137-218.

272 Baker, B., H. Diaz, W. Hargrove, and F. Hoffman (2010), Use of the KoppenTrewartha climate

273 classification to evaluate climatic refugia in statistically derived ecoregions for the People's

274 Republic of China, Climatic Change, 98(98), 113-131.

275 Beck, C., J. Grieser, M. Kottek, F. Rubel, and B. Rudolf (2005), Characterizing global climate

276 change by means of Koeppen climate classification, Beitrage zur globalen Klimatologie von

277 Wolken und Niederschlag, 51.

278 Box, E.O. (1981), Macroclimate and plant form. Junk, The Hague.

279 Box, E. O. (1996), Plant functional types and climate at the global scale, J. Veg. Sci., 7(3), 309280320.

281 Breshears, D. D., N. S. Cobb, P. M. Rich, K. P. Price, C. D. Allen, R. G. Balice, W. H. Romme,

282 J. H. Kastens, M. L. Floyd, and J. Belnap (2005), Regional vegetation die-off in response to 283 global-change-type drought, P. Natl Acad. Sci. USA, 102(42), 15144-15148.

284 Danneyrolles, V., Dupuis, S., Fortin, G., Leroyer, M., De Romer, A., Terrail, R., Vellend, M.,

285 Boucher, Y., Laflamme, J., Bergeron, Y., and Arseneault, D. (2019). Stronger influence of 286 anthropogenic disturbance than climate change on century-scale compositional changes in 287 northern forests. Nat. Commun. 10, 1265.

288 De Jong R, Schaepman ME, Furrer R, de Bruin S, Verburg PH (2013) Spatial relationship 289 between climatologies and changes in global vegetation activity. Global Change Biol., 19:1953$290 \quad 1964$ 
291 DeFries, R. S., Hansen, M. C., Townshend, J., Janetos, A. C., and Loveland, T. R. (2000), A new

292 global 1-km dataset of percentage tree cover derived from remote sensing, Global Change Biol., $2936,247-254$.

294 DeFries, R. S., and J. Townshend (1994), NDVI-derived land cover classifications at a global 295 scale, Int. J. Remote Sens., 15(17), 3567-3586.

296 DeFries, R. S., T. Rudel, M. Uriarte, and M. Hansen (2010), Deforestation driven by urban 297 population growth and agricultural trade in the twenty-first century, Nat. Geosci., 3(3), 178-181.

298 Ellis, E. C. (2011), Anthropogenic transformation of the terrestrial biosphere, Philosophical 299 Transactions of the Royal Society A, 369(1938), 1010-1035.

300 Ellis, E. C., J. O. Kaplan, D. Q. Fuller, S. Vavrus, K. K. Goldewijk, and P. H. Verburg (2013),

301 Used planet: A global history, P. Natl Acad. Sci. U S. A., 110(20), 7978-7985.

302 Ellis, E. C., K. Klein Goldewijk, S. Siebert, D. Lightman, and N. Ramankutty (2010), 303 Anthropogenic transformation of the biomes, 1700 to 2000, Global Ecol. Biogeogr., 19(5), 589304606.

305 Ellis, E. C., and N. Ramankutty (2008), Putting people in the map: anthropogenic biomes of the 306 world, Front. Ecol. Environ., 6(8), 439-447.

307 Foley, J. A., R. DeFries, G. P. Asner, C. Barford, G. Bonan, S. R. Carpenter, F. S. Chapin, M. T.

308 Coe, G. C. Daily, and H. K. Gibbs (2005), Global consequences of land use, Science, 309(5734), $309 \quad 570-574$.

310 Fraedrich, K., F. W. Gerstengarbe, and P. C. Werner (2001), Climate shifts during the last 
311 century, Climatic Change, 50(4), 405-417.

312 Gauthier, S., Bernier, P., Kuuluvainen, T., Shvidenko, A.Z., Schepaschenko, D.G. (2015), Boreal

313 forest health and global change, Science, 349, 819-822

314 Goldewijk, K. K., A. Beusen, G. Van Drecht, and M. De Vos (2011), The HYDE 3.1 spatially

315 explicit database of human - induced global land - use change over the past 12,000 years, Global

316 Ecol. Biogeogr., 20(1), 73-86.

317 Harris, I., Jones, P. D., Osborn, T. J., and Lister, D. H. (2014), Updated high-resolution grids of

318 monthly climatic observations-the CRU TS3. 10 Dataset, Int. J. Climatol, 34, 623-642

319 Holdridge, L. R. (1947), Determination of world plant formations from simple climatic data,

320 Science, 105, 267-268.

321 Holdridge, L. R. (1967), Life zone ecology, Tropical Science Center, San Jose, Costa Rica.

322 Kelly, A. E., and M. L. Goulden (2008), Rapid shifts in plant distribution with recent climate

323 change, P. Natl Acad. Sci. U S. A., 105(33), 11823-11826.

324 Köppen, W. (1936), Das geographische system der klimate

325 Kottek, M., Grieser, J., Beck, C., Rudolf, B., and Rubel, F. (2006), World map of the Köppen-

326 Geiger climate classification updated, Meteorol Z., 15, 259-263

327 Lewis, S. L., and M. A. Maslin (2015), Defining the anthropocene, Nature, 519(7542), 171-180.

328 Levavasseur, G., Vrac, M., Roche, D. M., and Paillard, D. (2012), Statistical modelling of a new 329 global potential vegetation distribution, Environ. Res. Lett., 7, 044019,

330 Li X, Chen G, Liu X, Liang X, Wang S, Chen Y, Pei F, Xu X (2017) A New Global Land-Use 
331 and Land-Cover Change Product at a 1-km Resolution for 2010 to 2100 Based on Human-

332 Environment Interactions. Annals of the American Association of Geographers 107:1040-1059

333 Liu, J., Liu, M., Deng, X., Zhuang, D., Zhang, Z., and Luo, D. (2002), The land use and land

334 cover change database and its relative studies in China, J. Geogr. Sci., 12, 275-282,

335 Loveland, T. R., Reed, B. C., Brown, J. F., Ohlen, D. O., Zhu, Z., Yang, L., and Merchant, J. W.

336 (2000), Development of a global land cover characteristics database and IGBP DISCover from 1

337 km AVHRR data, Int. J. Remote Sens., 21, 1303-1330

338 Lu, H., M. R. Raupach, T. R. McVicar, and D. J. Barrett (2003), Decomposition of vegetation

339 cover into woody and herbaceous components using AVHRR NDVI time series, Remote Sens.

340 Environ., 86(1), 1-18.

341 Mahlstein, I., J. S. Daniel, and S. Solomon (2013), Pace of shifts in climate regions increases

342 with global temperature, Nat. Clim. Change, 3(8), 739-743.

343 Pan, Y., X. Li, P. Gong, C. He, P. Shi, and R. Pu (2003), An integrative classification of

344 vegetation in China based on NOAA AVHRR and vegetation-climate indices of the Holdridge

345 life zone, Int. J. Remote Sens., 24(5), 1009-1027.

346 Pinzon, J. E. and Tucker, C. J. (2014), A non-stationary 1981-2012 AVHRR NDVI3g time

347 series, Remote Sens-Basel, 6, 6929-6960

348 Ramankutty, N., and J. A. Foley (1999), Estimating historical changes in global land cover:

349 Croplands from 1700 to 1992, Global Biogeochem. Сy., 13(4), 997-1027.

350 Song X, Hansen MC, Stehman SV, Potapov PV, Tyukavina A, Vermote EF, Townshend JR 
351 (2018) Global land change from 1982 to 2016. Nature 560:639-643

352 Tucker, C. J., J. E. Pinzon, M. E. Brown, D. A. Slayback, E. W. Pak, R. Mahoney, E. F. Vermote,

353 and N. El Saleous (2005), An extended AVHRR 8 - km NDVI dataset compatible with MODIS

354 and SPOT vegetation NDVI data, Int. J. Remote Sens., 26(20), 4485-4498.

355 Van Mantgem, P.J., Stephenson, N.L., Byrne, J.C., Daniels, L.D., Franklin, J.F., Fulé, P.Z.,

356 Harmon, M.E., Larson, A.J., Smith, J.M., Taylor, A.H. (2009), Widespread increase of tree

357 mortality rates in the western United States, Science, 323, 521-524

358 Wang A, Price DT, Arora V (2006) Estimating changes in global vegetation cover (1850-2100)

359 for use in climate models. Global Biogeochem. Cy. 20.

360 Zhang, X., Wu, S., Yan, X., and Chen, Z. (2017a). A global classification of vegetation based on

361 NDVI, rainfall and temperature. Int. J. Climat. 37, 2318-2324.

362 Zhang, X., Z. Xiong, X. Zhang, Y. Shi, J. Liu, Q. Shao, and X. Yan (2016), Using multi-model

363 ensembles to improve the simulated effects of land use/cover change on temperature: a case

364 study over northeast China, Clim. Dynam., 46(3), 765-778.

365 Zhang, X., and X. Yan (2014a), Spatiotemporal change in geographical distribution of global

366 climate types in the context of climate warming, Clim. Dynam., 43(3-4), 595-605.

367 Zhang, X., and X. Yan (2014b), Temporal change of climate zones in China in the context of

368 climate warming, Theor. Appl. Climatol., 115(1-2), 167-175.

369 Zhang, X., and X. Yan (2016), Deficiencies in the simulation of the geographic distribution of

370 climate types by global climate models, Clim. Dynam., DOI: 10.1007/s00382-015-2727-6. 
371 Zhang, X., Yan, X., and Chen, Z. (2017b). Geographic distribution of global climate zones under

372 future scenarios. Int. J. Climat. 37, 4327-4334.

373 Zhang, X., Xiong, Z., Zhang, X., Shi, Y., Liu, J., Shao, Q., and Yan, X. (2017c). Simulation of

374 the climatic effects of land use/land cover changes in eastern China using multi-model ensembles.

375 Global Planet. Change 154, 1-9.

376 Zhou, L., R. E. Dickinson, Y. Tian, R. S. Vose, and Y. Dai (2007), Impact of vegetation removal

377 and soil aridation on diurnal temperature range in a semiarid region: Application to the Sahel, P.

378 Natl Acad. Sci. U S. A., 104(46), 17937-17942.

379 Zhou, L., Y. Tian, R. B. Myneni, P. Ciais, S. Saatchi, Y. Y. Liu, S. Piao, H. Chen, E. F. Vermote,

380 and C. Song (2014), Widespread decline of Congo rainforest greenness in the past decade,

381 Nature, 509(7498), 86-90.

382

383 
384 Figure and table captions

385 Fig. 1. Sketch map for delimiting individual contributions of human disturbances and climate 386 changes on vegetation.

387 Fig. 2. Geographical distribution of existing vegetation types for the periods (A) 1982-1996 and 388 (B) 1997-2013, and (C) the differences between them. The black regions are those that have 389 undergone transformations in vegetation type.

390 Fig. 3. Geographical distribution of potential vegetation types for the periods (A) 1982-1996 and

391 (B) 1997-2013. The changes in (C) the potential vegetation and (D) actual vegetation between

392 two periods. The colors used for the potential vegetation types represent the same meanings as in

393 Fig. 2. The black regions are those that have undergone vegetation transformations.

394 Fig. 4. Geographical distribution of (A) existing vegetation types and (B) potential vegetation

395 types over the period 1982-2013, and (C) the differences between them. The differences show

396 the effects of the human activity on the distribution of vegetation types from no human

397 influenced period to 1982-2013.

398 Fig. 5. Human-induced vegetation changes from the period 1982-1996 to the period 1997-2013.

399 The black regions have undergone vegetation transformations as a result of human disturbance.

400 Fig. 6. (A) Changes in the existing vegetation in eastern China, (B) changes in the NDVI in

401 regions where existing vegetation changes were detected, $(\mathrm{C})$ changes in the NDVI over the 402 whole region, and (D) changes in land use detected using the land use data of Liu et al., (2002).

403 The red dot represents big city in eastern China. 
404 Table 1. Comparison of changed area of vegetation types in eastern China detected in this study

405 to those detected using the land use data of Liu et al., (2002). Liu' land use represents the land

406 use data of Liu et al., (2002). 
Figure 1

Sketch map for delimiting individual contributions of human disturbances and climate changes on vegetation.

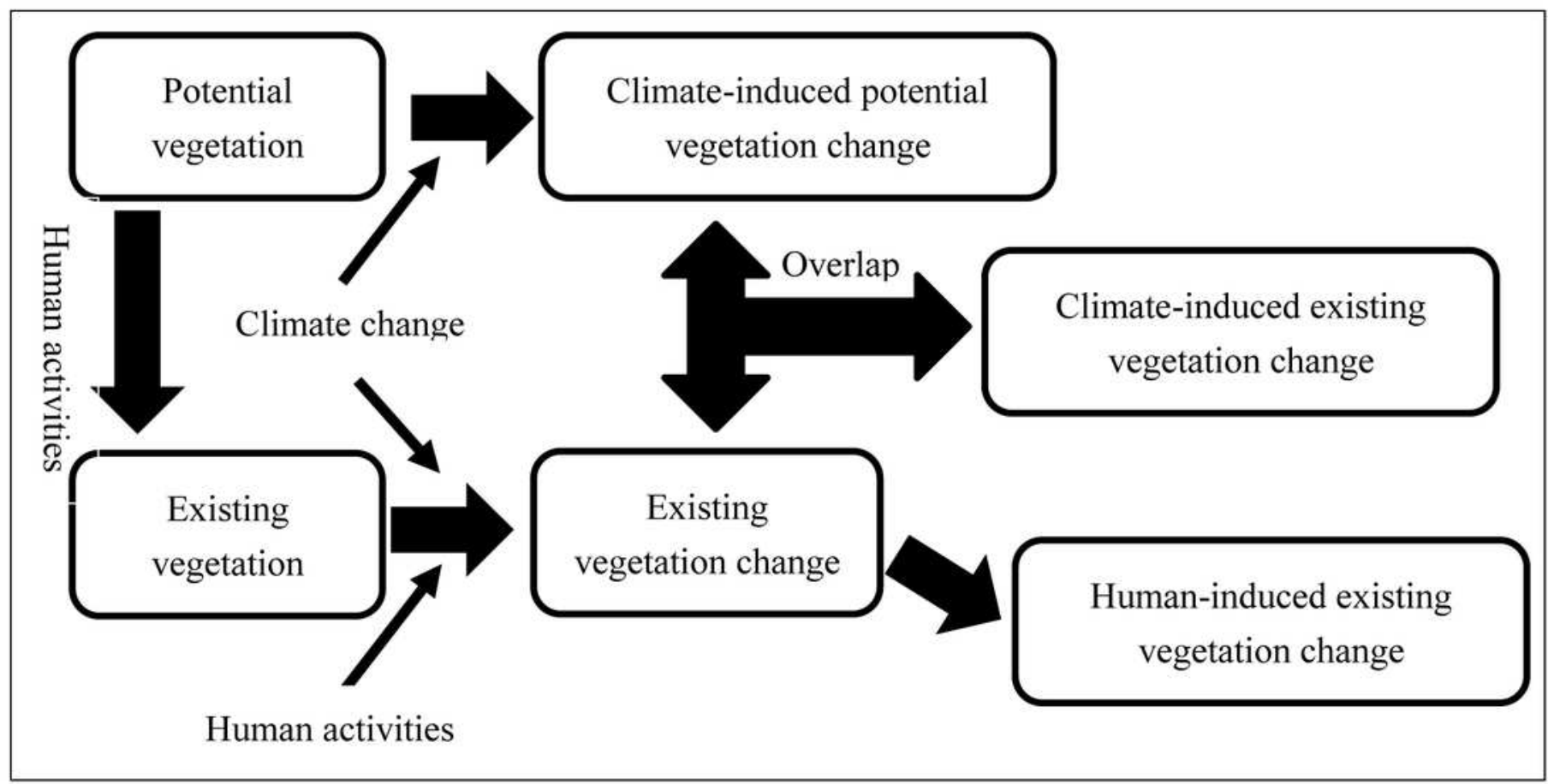




\section{Figure 2}

Geographical distribution of climatic vegetation types for $(A)$ the period 1982-1996 and (B) the period 1997-2013 and (C) the differences between them.

(A) Climatic vegetation types for the period 1982-1996 and (B) the period 1997-2013 and (C) the differences between them. The black regions are those that have undergone transformations in vegetation type.
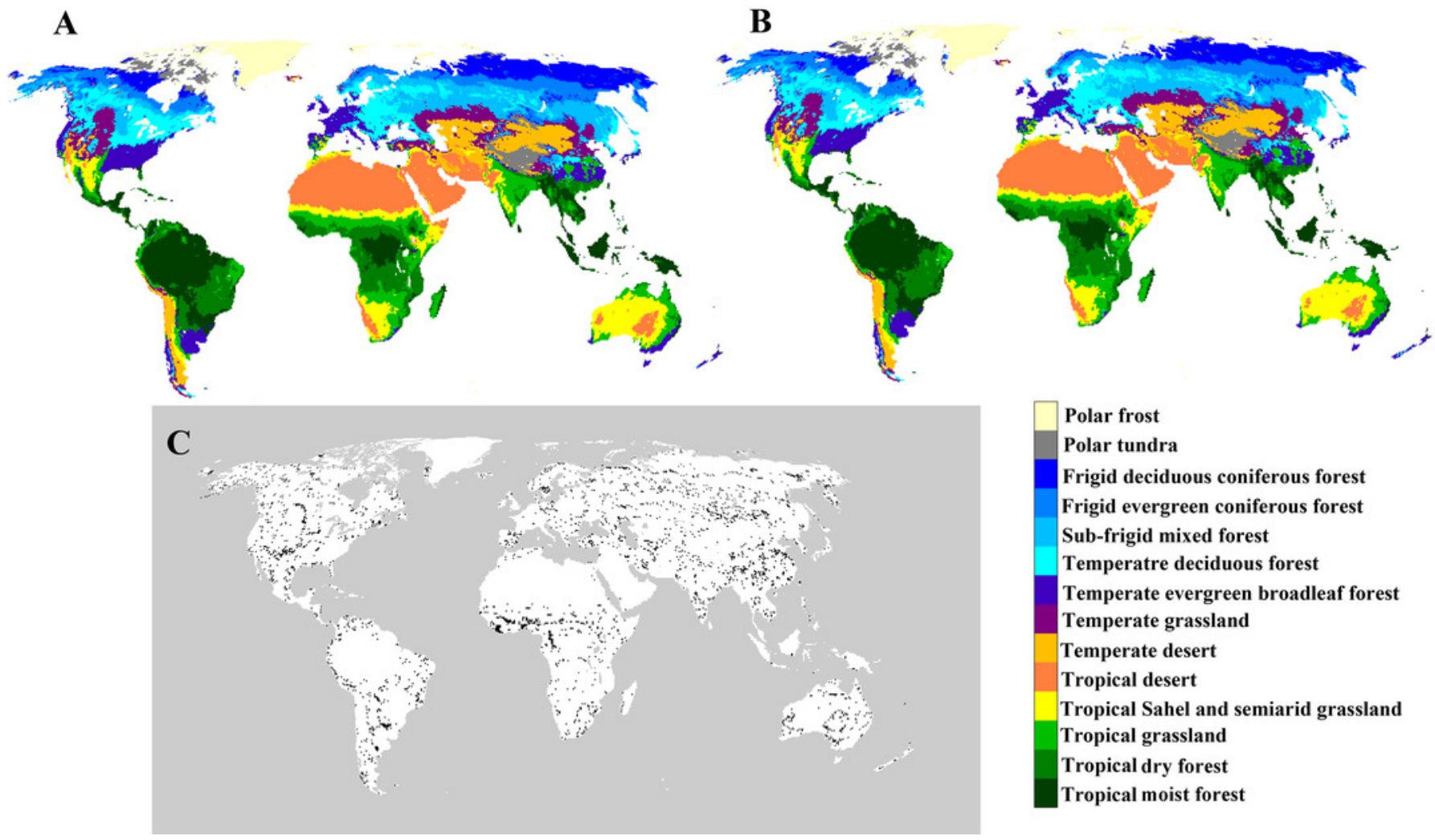

Polar frost

Polar tundra

Frigid deciduous coniferous forest Frigid evergreen coniferous forest Sub-frigid mixed forest

Temperatre deciduous forest

Temperate evergreen broadleaf forest

Temperate grassland

Temperate desert

Tropical desert

Tropical Sahel and semiarid grassland

Tropical grassland

Tropical dry forest

Tropical moist forest 


\section{Figure 3}

Geographical distribution of potential vegetation types for (A) the period 1982-1996 and (B) the period 1997-2013 and (C) the potential and (D) actual changes between them.

(A) Potential vegetation types for the period 1982-1996 and (B) the period 1997-2013 and

(C) the potential and (D) actual changes between them. The colors used for the potential vegetation types represent the same meanings as in Fig. 2 . The black regions are those that have undergone transformations in vegetation type.

A

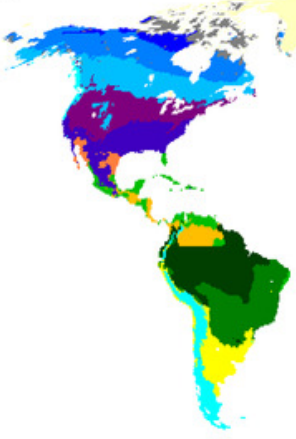

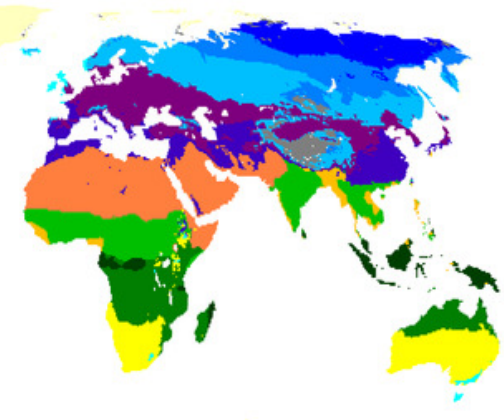

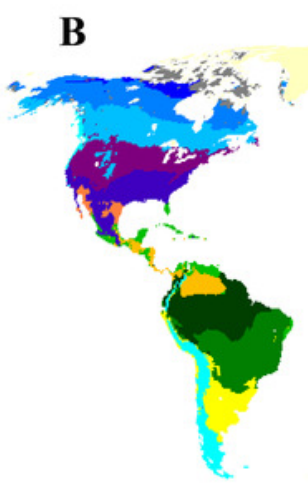

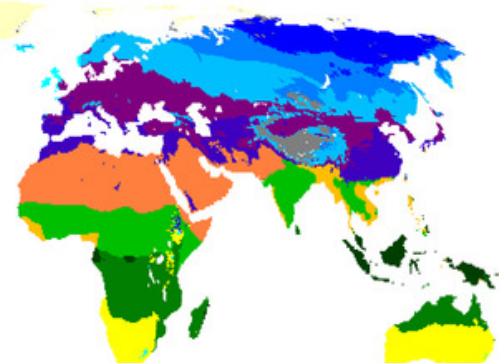

C

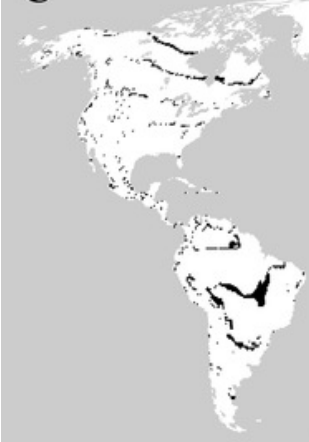

D

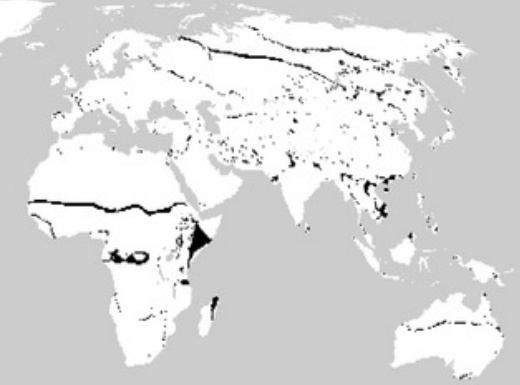

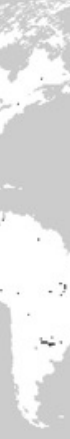




\section{Figure 4}

Geographical distribution of $(A)$ existing vegetation types and $(B)$ potential vegetation types over the period 1982-2013, and (C) the differences between them.

(A) Existing vegetation types and (B) Potential vegetation types over the period 1982-2013, and $(C)$ the differences between them. The differences show the effects of the human activity on the distribution of vegetation types from no human influenced period to 1982-2013.
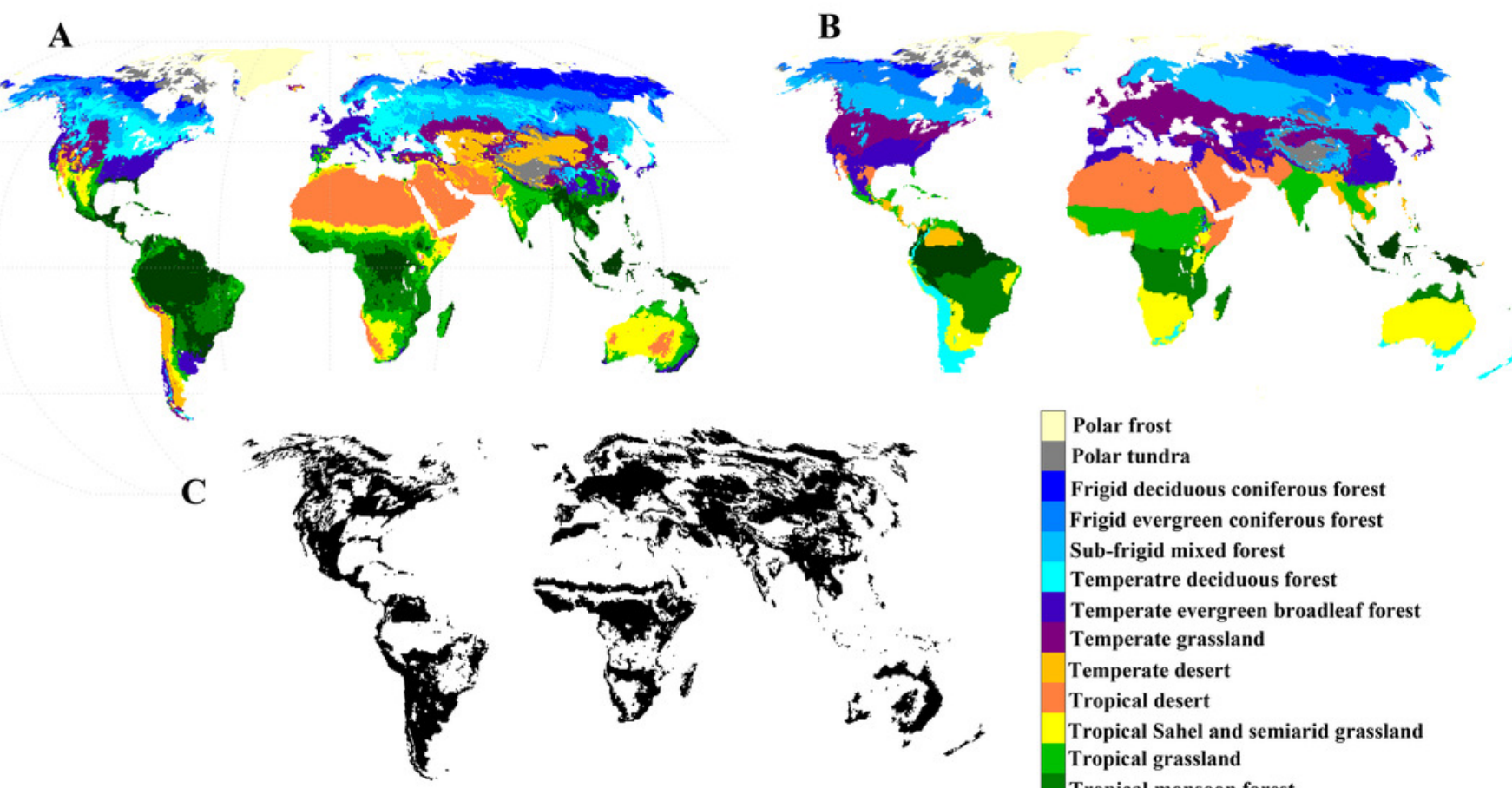

Polar frost

Polar tundra

Frigid deciduous coniferous forest Frigid evergreen coniferous forest Sub-frigid mixed forest Temperatre deciduous forest

Temperate evergreen broadleaf forest

Temperate grassland

Temperate desert

Tropical desert

Tropical Sahel and semiarid grassland

Tropical grassland

Tropical monsoon forest

Tropical forest 


\section{Figure 5}

Impact of human activity on the distribution of vegetation types over the period 1982-2013

The black regions are those that have undergone transformations in vegetation type as a result of human activity.

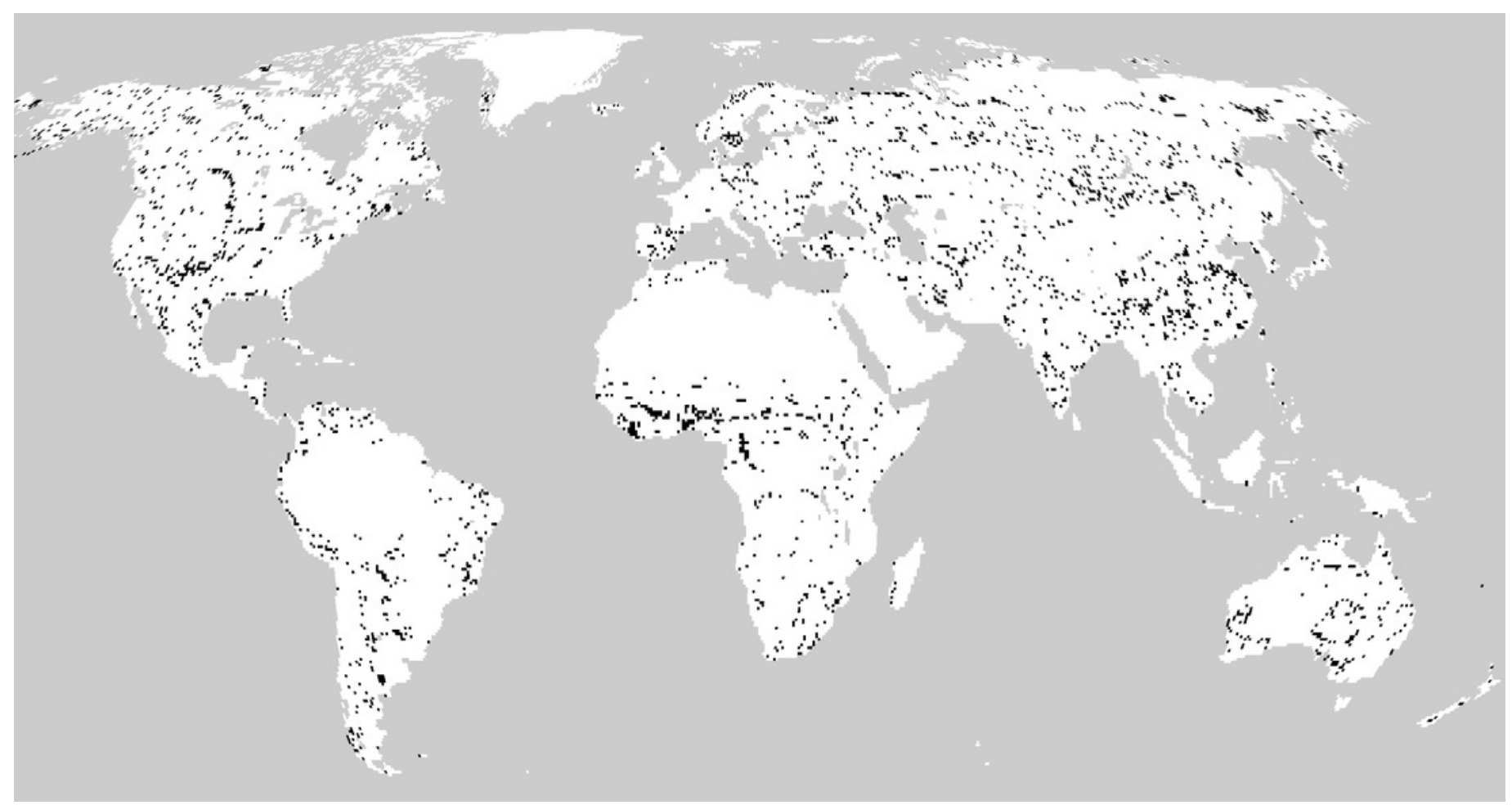




\section{Figure 6}

(A) Changes in the existing vegetation in eastern China, (B) changes in the NDVI in regions where existing vegetation changes were detected, (C) changes in the NDVI over the whole region, and (D) changes in land use detected using the land use data of Liu

(A) Changes in the existing vegetation in eastern China, (B) changes in the NDVI in regions where existing vegetation changes were detected, (C) changes in the NDVI over the whole region, and (D) changes in land use detected using the land use data of Liu. The red dot represents big city in eastern China. 

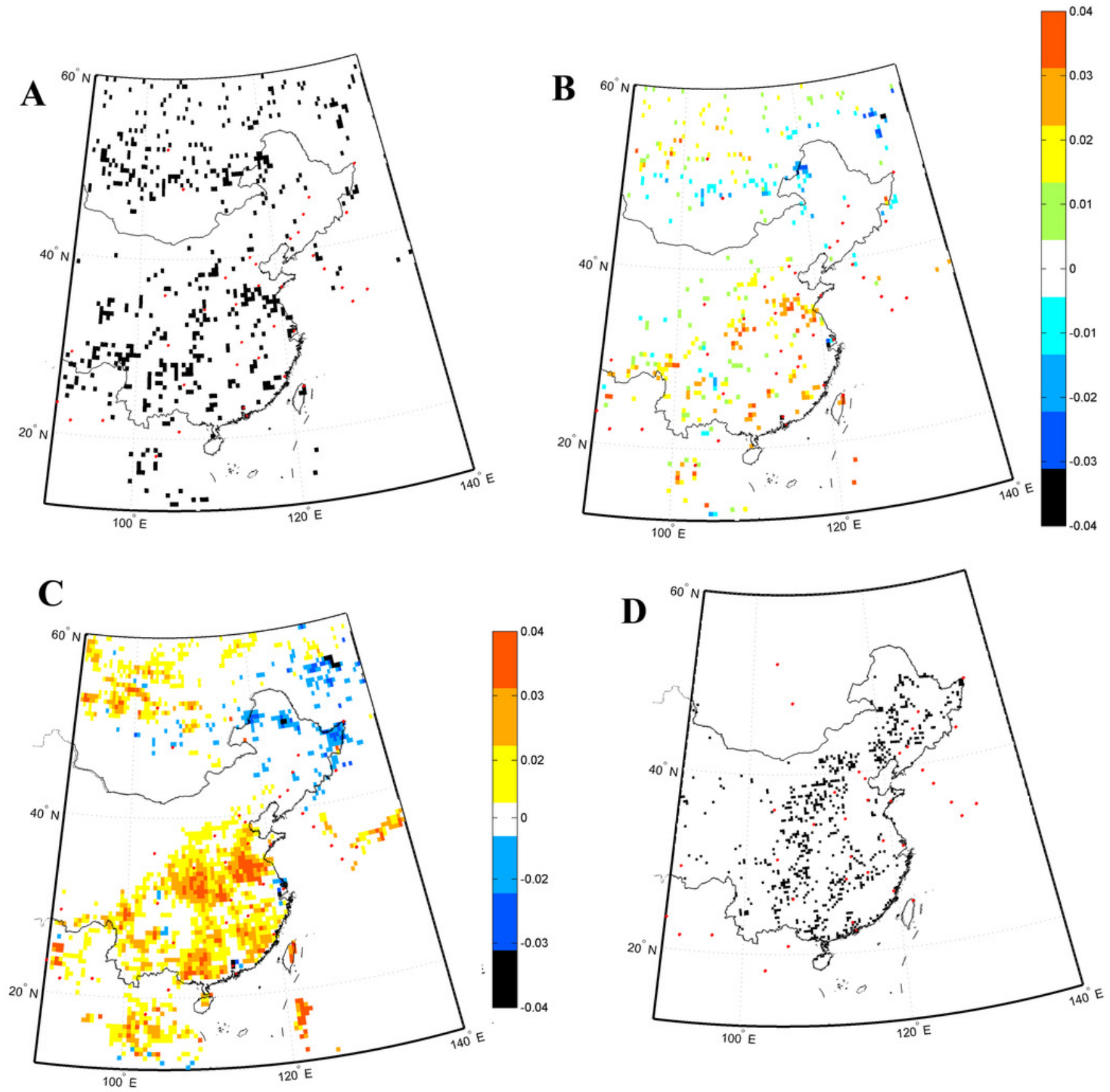


\section{Table $\mathbf{1}$ (on next page)}

Comparison of changed area of vegetation types in eastern China detected in this study to those detected using the land use data of Liu et al. (2002).

Liu' land use represents the land use data of Liu et al., (2002). 


\begin{tabular}{ccc}
\hline & \multicolumn{2}{c}{ Changed area of vegetation types $\left(10^{4} \mathrm{~km}^{2}\right)$} \\
\cline { 2 - 3 } & This study & Liu's land use \\
\hline $\begin{array}{c}\text { Temperate grassland } \\
\text { Temperate Evergreen } \\
\text { broadleaf forest }\end{array}$ & 7.5 & 6.4 \\
$\begin{array}{c}\text { Temperate Deciduous } \\
\text { forest }\end{array}$ & 7.7 & 6.1 \\
$\begin{array}{c}\text { Sub-frigid mixed forest } \\
\text { Frigid evergreen } \\
\text { coniferous forest }\end{array}$ & 6.7 & 4.6 \\
\hline
\end{tabular}

1 